\title{
Democratic Discourse in the Digital Public Sphere: Re-imagining Copyright Enforcement on Online Social Media Platforms
}

\author{
Sunimal Mendis
}

\begin{abstract}
Within the current European Union (EU) online copyright enforcement regime - of which Article 17 of the Copyright in the Digital Single Market Directive [2019] constitutes the seminal legal provision-the role of online content-sharing service providers (OCSSPs) is limited to ensuring that copyright owners obtain fair remuneration for content shared over their platforms (role of "content distributors") and preventing unauthorized uses of copyright-protected content ("Internet police"). Neither role allows for a recognition of OCSSPs' role as facilitators of democratic discourse and the duty incumbent on them to ensure that users' freedom to engage in democratic discourse are preserved. This chapter proposes a re-imagining of the EU legal framework on online copyright enforcement-using the social planning theory of copyright law as a normative framework - to increase its fitness for preserving and promoting copyright law's democracy-enhancing function.
\end{abstract}

Online social media platforms that are open to members of the public (e.g., Facebook, Twitter, YouTube, TikTok) constitute digital spaces that provide tools and infrastructure for members of the public to dialogically interact across geographic boundaries. Given the high numbers of users they attract, the substantial amount of discourse taking place over these platforms, and its capacity to influence contemporary public opinion, it is possible to define them as a core component of the contemporary digital public sphere.

As envisioned by Habermas (1989), the digital public sphere has a key function in fostering democratic discourse which, within the deliberative democratic ideal, is crucial for furthering the democratic decision-making process. Thus although typically subject to private ownership, given their character as a component of the digital public sphere, it is necessary that the governance of online social media platforms reflects this private-public partnership and is aimed towards advancing the public interest in fostering democratic discourse.

\footnotetext{
S. Mendis ( $ه)$

Tilburg University, Tilburg, The Netherlands e-mail: L.G.S.Mendis@tilburguniversity.edu 
A precise definition of the term "democratic discourse" is difficult to come by. However, Dahlberg's concept of rational-critical citizen discourse provides a notion of public discourse that is autonomous from both state and corporate power and enables the development of public opinion that can rationally guide democratic decision-making (Dahlberg 2001). This pre-supposes the ability of members of the public to engage in autonomous self-expression (free of suppression and manipulation by corporate or state power), leading to a proliferation of diverse viewpoints that can be the subject of open, inclusive, and deliberative discussion. The value attributed to fostering democratic discourse within the European Union (EU) is underscored by the fundamental rights to freedom of expression, information, arts, and culture guaranteed by the European Convention on Human Rights (ECHR 1953) and the EU Charter of Fundamental Rights (CFR 2000).

Platforms' owners or-as they are commonly referred to in copyright law discourse-online content-sharing service providers (OCSSPs) have traditionally been viewed as "mere conduits" that provide the infrastructure required for third parties to disseminate information. However, there is increasing recognition of OCSSPs' capacity to influence and direct the discourse taking place on their platforms, particularly by means of content moderation (Pasquale 2010). Content moderation refers to the governance mechanism through which OCSSPs ensure that content shared on the platforms comply with applicable legal rules and regulatory requirements. In the context of copyright law, for instance, this would refer to OCSSPs' ability to take down or flag copyright-infringing content. Content moderation enables OCSSPs to both restrict users' ability to engage in discourse (e.g., by suppressing copyright-infringing content or blocking user accounts) and to exercise a normative influence in shaping user behavior and perceptions (e.g., by interpreting the scope of a copyright exception in their terms of service). Hence, although they lack editorial control over content shared on their platforms, OCSSPs fulfill a crucial role as curators of online discourse and as arbiters of online copyright enforcement. In executing this curatorial function, OCSSPs have the capacity to function as facilitators of democratic discourse by ensuring that their content moderation systems are designed and implemented in a manner that minimizes the negative effects of harmful discourse through the suppression of illegal (e.g., copyright-infringing) content while safeguarding users' freedom to engage with creative and cultural content in socially valuable ways, thereby promoting robust public discourse.

The creation and sharing of user-generated content (UGC) is a primary means by which users of social media platforms engage in discourse. Remix practices that involve the re-use and re-interpretation of existing informational and cultural content (e.g., texts, images, music) in creative ways for purposes of social commentary and critique (e.g., parodies, memes) typically for non-commercial purposes constitute a particularly powerful mode of dialogic interaction that enables the dissection of contemporary narratives to create new meaning by challenging established ideological assumptions and stereotypes (Peverini 2015). It is noteworthy that copyright law recognizes the importance of facilitating the re-use and re-interpretation of informational and cultural content for purposes of social commentary and critique by means of granting specific exceptions and limitations that enable the use of 
copyright-protected content for purposes of quotation, criticism, review, and parody. These exceptions qualify as user privileges ${ }^{1}$ or freedoms that enable users to engage with copyright-protected content without fear of legal sanction. Thus, ensuring the effective protection of these users' freedom to engage with copyright-protected content for purposes of social commentary and critique gains paramount importance in fostering democratic discourse on social media platforms. Accordingly, the Court of Justice of the European Union (CJEU) has on multiple occasions underscored the importance of interpreting such exceptions and limitations in a manner that ensures the protection of users' freedom of expression (Article 11 CFR) and freedom of the arts (Article 13 CFR) while striking a fair balance with copyright owners' fundamental right to the protection of their intellectual property (Article 17(2) CFR). ${ }^{2}$

However, the existing EU law framework on copyright enforcement in the online sphere—of which Article 17 of the Copyright in the Digital Single Market Directive [2019] constitutes the seminal legal provision - is rooted in the utilitarian viewpoint that envisages copyright as an instrument for incentivizing the production of creative content by granting authors a means of obtaining an adequate reward for their intellectual investment. This is reflected in the underlying policy rationale for Article 17 which is bridging the "value gap" that purportedly stems from the undercompensation of copyright owners (especially in the music industry) for copyright-protected content shared by users over online content-sharing platforms. Thus, the primary goal of Article 17 is to protect the economic interests of copyright owners by preventing the unauthorized distribution of copyright-protected content over online platforms and ensuring their ability to obtain fair remuneration through licensing. Article 17 seeks to achieve this goal by imposing a heightened duty of care and an enhanced degree of liability on OCSSPs for copyright-infringing content shared by users over their platforms. Consequently, OCSSSPs are compelled to adopt a more stringent regulatory approach toward preventing the sharing of unauthorized content, for instance, by engaging in more expansive monitoring and filtering of UGC content with the aid of algorithmic content moderation tools (Frosio and Mendis 2020).

Conversely, the preservation of users' freedom is rendered peripheral to the core economic aim of ensuring fair remuneration to copyright owners. Although Article 17(7) enunciates that OCSSPs' efforts to suppress infringing content should not result in preventing the availability of non-infringing content (as in the case where the use of copyright-protected content falls within a legally granted exception), no explicit liability is imposed on OCSSPs for the wrongful suppression of legitimate uses of copyright-protected content. Neither are OCSSPs imposed with enforceable

\footnotetext{
${ }^{1}$ It is noted that in the decisions delivered in C-469/17 Funke Medien NRW [2019] ECLI:EU:C: 2019:623 and C-516/17 Spiegel Online [2019] ECLI:EU:C: 2019:625 the Court of Justice of the European Union (CJEU) interpreted the exceptions and limitations to copyright provided under Article 5 of the EU Copyright Directive (2001) as user rights as opposed to mere user privileges.

${ }^{2}$ For instance, Case C-201/13 Deckmyn v Vandersteen [2014] ECDR 21, C-469/17 Funke Medien $N R W$ [2019] and C-516/17 Spiegel Online [2019]. See also C-476/17 Pelham and Others [2019] ECLI:EU:C: 2019:624.
} 
obligations to safeguard users' freedom. On the other hand, Article 17(7) does underscore the importance of ensuring that users are able to rely on existing exceptions and limitations for quotation, criticism, review and parody, caricature and pastiche, but this responsibility is assigned to Member States as opposed to OCSSPs.

Thus, the online copyright enforcement regime introduced by Article 17 is skewed in favor of protecting the economic interests of copyright owners with less emphasis being placed on the protection of users' freedom to engage in democratic discourse. Pursuant to a simple "cost-benefit" analysis, it is intuitive that it would be less costly for OCSSPs to block or remove questionable content rather than to take the risk of incurring liability under Article 17. This means that OCSSPs would be incentivized to calibrate their content moderation systems to suppress potentially copyright-infringing content without properly analyzing the legality of that content under applicable copyright exceptions, thereby increasing the risks of "collateral censorship."

As such, within the present EU legal framework on online copyright enforcement, the role of OCSSPs is limited to ensuring that copyright owners obtain fair remuneration for content shared over their platforms (role of "content distributors") and preventing unauthorized uses of copyright-protected content ("Internet police"). Neither role allows for a recognition of OCSSPs' role as facilitators of democratic discourse and the duty incumbent on them pursuant to that role to ensure that users' freedom to engage in democratic discourse are preserved.

While acknowledging the primacy of the utilitarian-based incentive theory as the dominant narrative of contemporary EU copyright law framework, this chapter proposes a re-imagining of the EU legal and policy framework on online copyright enforcement using the social planning theory of copyright law as a parallel theoretical framework. The social planning theory as advanced in the writings of ElkinKoren (1995), Netanel (1996), and Fisher (2001) is rooted in the ideological argument that copyright can and should be shaped to foster a just and attractive democratic culture (Fisher 2001, p. 179). While affirming the role of copyright in preserving the incentives of authors to produce and distribute creative content, the social planning theory envisions a broader purpose for copyright law in promoting the discursive foundations for democratic culture and civic association (Netanel 1996). Thus, it prescribes that protecting the interests of copyright owners must be tempered by the overarching aspiration of sustaining a participatory culture (Fisher 2001), which in turn necessitates the adequate preservation of users' freedom to engage with copyright-protected content for purposes of democratic discourse. Accordingly, the social planning theory emphasizes the need to calibrate copyright law to minimize impediments to the public's ability to engage with content in socially valuable ways while, at the same time, protecting the legitimate interests of copyright owners (Netanel 1996).

I argue that the democratic function of copyright law, as exemplified by the social planning theory, offers a normative basis for re-imagining the role of OCSSPs within EU copyright law. This would firstly entail a re-affirmation that the protection of users' freedom to benefit from copyright exceptions (particularly those exceptions 
that are vital for enabling democratic discourse such as quotation and parody) is central to copyright law's purpose and as such should be granted equal weight and importance as the protection of the economic rights of copyright owners. This would enable the protection of users' freedom to be re-located from the periphery of copyright law policymaking (to which it is currently relegated) to the center of the discussion. Furthermore, it would provide a normative basis for courts to engage in a more expansive teleological interpretation of copyright exceptions with a view to advancing the democracy-enhancing function of copyright law. Secondly, it would pave the way for acknowledging the potency of content moderation systems to direct and influence public discourse on social media platforms. This would provide a basis for OCSSPs to be imposed with positive obligations to ensure that content moderation systems are designed and implemented in a manner that provides adequate protection to users' freedom, thereby transforming their role from being mere "content distributors" or the "Internet police" to active partners in fostering democratic discourse in the digital sphere.

Within the present EU copyright law discourse that is grounded on the utilitarian approach, arguments for preserving and promoting democratic discourse on social media platforms are typically rooted in fundamental rights justifications, particularly the freedom of expression. Thus, fostering a participatory culture and robust dialogic interaction in the online sphere tends to be viewed as something exogenous to copyright law's objectives and, often, as something that comes into conflict with it. Espousing the social planning theory as a parallel theoretical framework would bring about a paradigm shift that enables the protection of democratic discourse to be seen as something that is endogenous - and in fact fundamental - to copyright's purpose and provide a solid normative basis for re-imagining the EU legal framework on online copyright enforcement to increase its fitness for preserving and promoting copyright law's democracy-enhancing function.

\section{References}

Dahlberg, L. (2001). The Internet and democratic discourse: Exploring the prospects of online deliberative forums extending the public sphere. Information, Communication \& Society, 4(4), pp. 615-633.

Elkin-Koren, N. (1995). Copyright and Social Dialogue on the Information Super Highway: The Case Against Copyright Liability of Bulletin Board Operators. Cardozo Arts \& Entertainment Law Journal, 13, pp. 346-411.

Fisher, W. (2001). Theories of Intellectual Property. In: S.R. Munzer, ed., New Essays in the Legal and Political Theory of Property. Cambridge: CUP, pp. 168-199.

Frosio, G. and Mendis, S. (2020). Monitoring and Filtering: European Reform or Global Trend?'. In: G. Frosio ed., The Oxford Handbook of Intermediary Liability. Oxford: OUP. 
Habermas, J. (1989). The Structural Transformation of the Public Sphere: An Inquiry into a Category of Bourgeois Society. Translated by Thomas Burger. Cambridge: MIT.

Netanel, N.W. (1996). Copyright in a Democratic Civil Society. Yale Law Journal, 106, pp. 283-387.

Pasquale, F. (2010). Beyond Innovation and Competition: The Need for Qualified Transparency in Internet Intermediaries. Northwestern University Law Review, 104 (1), pp. 105-173.

Peverini, P. (2015). Remix Practices and Activism. In: E. Navas, O. Gallagher, x. burrough, eds., The Routledge Companion to Remix Studies. New York: Routledge, pp. 333-345.

Open Access This chapter is licensed under the terms of the Creative Commons Attribution 4.0 International License (http://creativecommons.org/licenses/by/4.0/), which permits use, sharing, adaptation, distribution and reproduction in any medium or format, as long as you give appropriate credit to the original author(s) and the source, provide a link to the Creative Commons license and indicate if changes were made.

The images or other third party material in this chapter are included in the chapter's Creative Commons license, unless indicated otherwise in a credit line to the material. If material is not included in the chapter's Creative Commons license and your intended use is not permitted by statutory regulation or exceeds the permitted use, you will need to obtain permission directly from the copyright holder. 